\title{
DIGNIFICACIÓN DEL SER MUJER, CONSOLIDACIÓN DE DERECHOS, ROL DE LA PSICOLOGÍA JURÍDICA LINA MARIA FONSECA ORTIZ - COLOMBIA
}

\author{
Lina María Fonseca Ortiz \\ Universidad santo Tomás \\ https://psicologiajuridica.org/archives/2956
}

La sociedad colombiana, contempla diversas realidades. Realidades que en muchas ocasiones resultan complejas de vivir, comprender y ajustar a verdaderos estados sociales, que favorezcan el desarrollo libre e integral de las personas, en especial, de las mujeres, por cuanto, una de esas diversas realidades, es la violencia contra la mujer.

Violencia que ha sido silenciada por muchos años, encontrando diferentes formas de vulnerarla y agredirla, dejando huellas, físicas, emocionales y morales, que quizás, son imposibles de borrar. Hasta hace poco se ha hecho más cercana y visible a la sociedad dicha forma de violencia, sin que ello, necesariamente represente la consolidación de una conciencia más limpia y verdadera frente al papel dignificador de la mujer.

El 08 de marzo se celebra el Día Internacional de la Mujer, sin embargo, muchos olvidan que más allá de la celebración, se conmemora la lucha por los derechos de las mujeres, construida a través de grandes desafíos, la consecución de ciertos beneficios y algunos cambios de orden social. A pesar de esta lucha, aún en varias partes del mundo se vive la transgresión hacia la mujer como consiga de la sociedad.

Por mucho tiempo el hombre ha olvidado la verdadera esencia del ser mujer, minimizándola solo a su cuerpo, dejando de lado la gran experiencia que encierra dicho cuerpo, pues, la sociedad se encarga de vender un prototipo de mujer ajeno a ella. Por aprendizaje y por contexto, se le enseña a la mujer qué no debe hacer, sin embargo, se olvida algo más importante, la enseñanza y la vivencia del ser, la experiencia de reconocimiento y valoración propia, la búsqueda del ser feliz como persona, como ser humano, como mujer, lo que desencadena en la peyorización de la misma y la disminución de su autoestima. Se debe comprender que El ser mujer se constituye en la construcción, desarrollo y consolidación de su Ser integral, el cual, inicia por el reconocimiento de la realidad propia del Ser como persona, reconociendo y conociendo su integralidad, entendiendo, que no es un ser fraccionado y dirigido a alimentar una sociedad de consumo o para responder a un ideal socialmente aceptado.

Desde tiempo atrás, se ha degradado su ser a una experiencia pobre y marginal, considerando la fragilidad de su ser, como inferior. Por ello, para muchos es normal y natural abusar de la mujer, olvidando lo excepcional y valiosa que es, por el solo hecho de ser mujer, pues, ella es el sustento de una sociedad, es quien engendra el ser mismo de la humanidad.

Con motivo de la celebración del día de la mujer en el país, el Presidente Santos, hizo un reconocimiento para ellas, [..] "celebramos los avances sociales, económicos y políticos [...] episodios claves de nuestra historia que inspiraron la justa reivindicación de los derechos femeninos [..] estamos enfocados en proteger a la mujer y trabajaremos para que cada municipio del territorio nacional se una a este propósito". (Santos, J. M. 2012)

Paralelo a ello, el presidente Santos y varios gobernadores firmaron un acuerdo nacional para la defensa de los Derechos de las mujeres, el cual, tiene como propósito avanzar en la lucha contra la discriminación hacia ellas en el país. A continuación, un extracto del pronunciamiento hecho al respecto [...] "Aquí estamos comprometidos con esta causa de eliminar la discriminación y la violencia contra la mujer". El acuerdo contempla la necesidad de emprender acciones para disminuir los índices de violencia contra el sexo femenino y acordar estrategias de sensibilización entres los menores de edad frente a la defensa de la igualdad entre hombres y mujeres. [..] (El tiempo.com, 2012) 
Recientemente se ha vivido una forma de violencia contra la mujer, que puede resultar aterradora, fría y despiadada para muchas mujeres y algunos hombres, pues, no sólo conciben en la mujer, un ser valioso que necesita ser cuidada y protegida, sino que reconocen en el hecho mismo un acto inhumano, que transgrede el derecho de la integridad física y psicológica, así como el libre desarrollo de la personalidad, con lo cual, se vulnera su ser persona. Esta forma de violencia corresponde al ataque con ácido. En el país cada día aumentan las víctimas a manos de este flagelo, por ello, a continuación, se presentan algunos de los casos que aún resuenan en las víctimas y sus familias.

[...] Mujeres como María Cuervo, de 41 años, además del dolor que da pasar por el quirófano, pelean contra el miedo de enfrentarse a un espejo. Hace seis años, un 8 de marzo, fue atacada cuando en Colombia se celebraba el Día de la Mujer. "Triste, ¿cierto?", dice ella. De su casa retiraron, por súplica suya, los espejos. Se enclaustró durante un año, tiempo que tardó para volver a ver su rostro reflejado. "Le tenía pánico al espejo". De esa época para acá, le han efectuado 50 cirugías. (Neira, A. 2011)

En palabras de Viviana, otra de las víctimas "No somos una cicatriz, seguimos siendo personas, seres humanos y madres, y el tener una marca no nos hace menos. Tenemos virtudes, como cualquier persona. Esos detalles no los han tenido en cuenta en ningún lado" (Valbuena, J. 2012)

De igual manera, Gina señala "Las huellas que deja no son sólo físicas, también son sicológicas", tras recordar que su primera reacción al verse desfigurada fue encerrarse. Con el paso del tiempo venció el miedo y salió a buscar trabajo. "Pero nadie me empleaba al verme así". "Cuando una es atacada con ácido no recibe la solidaridad de las autoridades". (El tiempo.com, 2012)

A la luz de estos testimonios, se puede entender como las victimas perciben cierta inoperancia de las entidades que deberían resguardarlas, por ello, no sólo basta prohibir la venta de ácido o incrementar su costo en el mercado, puesto que, fácilmente puede convertirse en un mercado ilegal. Tampoco basta con fortalecer la estructura de las Comisarías de Familia, entidades que en su mayoría reciben las denuncias de violencia intrafamiliar. Por cuanto, como menciona Neira, A. (2011) en un país donde se le rinde culto a la belleza, los agresores han encontrado en este cruel y horrendo método una forma de venganza inimaginable. Es el crimen perfecto: asesinan la belleza, la víctima jamás olvida al victimario y este sigue libre, como si nada. Al retomar las palabras de Neira, su puede entender como la impunidad y el abandono que viven y experimentan las víctimas se vuelve parte inherente de su existir, generando su invisibilización.

Cabe entonces preguntar ¿La comisión de esta conducta puede considerarse como delito? ¿Puede tipificarse como típica, antijurídica y culpable? ¿Lesiona un bien jurídico tutelado? Pues bien, jurídicamente están tipificadas como lesiones personales, que en la mayoría de las veces quedan en la impunidad, por la dificultad que representa probar la autoría del hecho, adicional a ello, la mayoría de los casos responden a violencia intrafamiliar.

Sin embargo, acorde al código penal y de procedimiento penal y lo contemplado en el capítulo tercero - De las lesiones personales- específicamente en lo consignado en el artículo 113 respecto a la deformidad, refiere, si el daño consistiere en deformidad física transitoria, la pena será de prisión de uno (1) a seis (6) años [.. ] si fuere permanente, la pena será prisión de dos (2) a siete (7) años y multa de veinticinco (25) a treinta y seis (36) salarios mínimos legales mensuales vigentes. Si la deformidad afectare el rostro, la pena se aumentará hasta en una tercera parte. Asimismo, el artículo 115 sobre la perturbación psíquica menciona, si el daño consistiere en perturbación psíquica transitoria, la pena será de prisión de dos (2) a siete (7) [..] si fuere permanente, la pena será prisión de tres (3) a nueve (9) años y multa de veintisiete (27) a cincuenta (50) salarios mínimos legales mensuales vigentes. (Arboleda, M. 2011) 
Por otro lado, y con el ánimo de respaldar los cuestionamientos anteriores sobre la punibilidad de la conducta, según el artículo 9 del título I sobre las normas rectoras de la Ley penal colombiana, para que la conducta sea punible se requiere que sea típica, antijurídica y culpable. Así mismo, el capítulo único de la conducta punible, presenta las modalidades de la misma, a saber: dolosa, culposa o preterintencional. La conducta es dolosa cuando el agente reconoce los hechos constitutivos de la infracción penal y quiere su realización, es decir, cuando dirige su conducta a producir un daño a bienes tutelados por el bien jurídico. (Régimen penal colombiano, 2006)

De la mano con lo anteriormente expuesto, el código penal, hace las siguientes precisiones, frente a las consecuencias jurídicas de la conducta punible "la pena tiene en nuestro sistema jurídico un fin preventivo, que se cumple básicamente en el momento del establecimiento legislativo de la sanción [..] un fin retributivo, que se manifiesta en el momento de la imposición judicial de la pena, y un fin resocializador que orienta la ejecución misma, de conformidad con los principios humanistas y las normas de derecho internacional adoptadas" (C. Const., Sent. C-430, sep. 12/96. M.P. Carlos Gaviria Díaz, citado en el Régimen penal colombiano, 2006)

No obstante, no sólo es necesario considerar, lo expuesto dentro del código penal para las consecuencias jurídicas sobre dicha conducta punible y dolosa, concurre entonces la necesidad de reflexionar sobre el papel que desempeñan todos los actores que de una $u$ otra forma se ven involucrados en este tipo de hechos, por cuanto, más allá de imponer sanciones para el victimario, es necesario, posibilitar espacios que soporten la dignificación de la mujer agredida, que garanticen el restablecimiento de derechos y la atención frente al daño psicológico causado, entre otros.

Con base en lo anterior, es pertinente mencionar lo planteado por Soria (1993) con respecto a los efectos psicosociales que se pueden presentar en las victimas, aparición de shock o desorganización, siendo el nivel afectivo la clave para su comprensión, pues, la afectividad de la víctima se ve dominada por sentimientos de vulnerabilidad, impotencia, conmoción, bloqueo cognitivo, entre otros. Seguida de una segunda etapa caracterizada por la reevaluación cognitivo - conductual, intentado integrar el evento dentro de sus esquemas personales y escalas de valores. Por último, una vez el miedo y la ira descienden, se adentran en fase de reorganización, donde el impacto del evento delictivo se resuelve mediante el establecimiento de defensas más efectivas.

Al saber entonces, que los procesos de asimilación de un evento delictivo toman gran variedad de recursos personales por parte de las víctimas, esto con relación al daño psicológico derivado (Echeburúa, Corral y Amor, 2002), cabe otra pregunta ¿cuál es el papel que se debe asumir en el proceso de impartir justicia, reparar a las mujeres víctimas y al momento de proporcionarles las condiciones que garanticen la protección de los bienes jurídicos tutelados? Para contestar esta pregunta habrá de considerarse lo planteado por Fajardo y García (2011) cuando proponen considerar el concepto de utopía como la búsqueda de la justica social fundamentada en el reconocimiento de los derechos y la necesidad de dignificar su ser.

Al partir de la necesidad de dignificar el ser, es plausible comprender diferentes formas de ejercer la psicología jurídica, lo cual, se podría sustentar en el uso alternativo del Derecho, que en palabras de Fajardo y García (2011) propone una práctica judicial emancipadora para el beneficio de sectores sociales menor favorecidos, a través de una aplicación diferente del derecho vigente, sin apartarse del sistema normativo oficial, ni generando nuevas categorías jurídicas; lo anterior enmarcado dentro del propósito de superar el trato excluyente e injusto que pueda tener lugar al interior de una sociedad.

Por ello, es viable a la luz del uso alternativo de derecho, pensar en el rol de la psicología jurídica y renovadas formas de ejercerla, tendiendo como base el conocimiento de la psicología humana. Si bien, el derecho busca regular la conducta, la psicología explica la comisión de la misma, por lo anterior, concebirla como estandarte en la construcción de 
espacios que permitan generar estrategias para la consolidación y materialización de derechos que promuevan la resignificación de la mujer como ser integral, es trabajo que concierne a los psicólogos jurídicos, pues, requiere la participación activa e interdisciplinaria, que favorezca el reconocimiento de derechos, concediendo espacios de reflexión que vislumbre la correlación de conocimientos y saberes, para enriquecer y mejorar, no sólo la gestión al interior de las entidades, sino que busque encaminar y promover el diseño, construcción, consolidación e implementación de políticas públicas, programas de prevención y atención, que susciten la defensa, garantía y protección de los derechos, de manera ética y humana para las mujeres que han sido víctimas de esta forma de violencia.

No es suficiente con la identificación del victimario, ni con la imposición de penas. Para las víctimas, más allá de la posible restitución, reparación o castigo impuesto por la ley, es necesaria la reivindicación de sus derechos vulnerados, es necesario proporcionarles herramientas que garanticen su adecuada inclusión en la sociedad luego de haber sido víctimas del hecho, por cuanto, al regresar a la sociedad, se evidencia nuevamente una victimización, pues, la sociedad en si misma las estigmatiza y relega, es necesario que como sociedad Colombiana se viva un proceso de concienciación frente a la dignificación del ser mujer, con el fin de establecer formas dignas de vivir y convivir en sociedad.

Al considerar lo expuesto en este documento, es cognoscible la formación de psicólogos jurídicos que viabilicen y sustenten formas alternativas de tratar a estas mujeres con base en el reconocimiento de su ser persona, más allá de concebirlo como un acontecer legal desde el punto de vista del derecho, la intencionalidad es entonces la humanización de la justicia, promover líneas de acción que a través de la construcción de modelos, protocolos o guías sustenten el quehacer profesional y favorezcan la ayuda y atención a las víctimas.

¿Qué constituye el ser del ejercicio profesional? ¿Por qué no constituirlo en virtud de procesos más humanizados en pro del devenir propio del ser persona? Con base en ello, no se puede pensar la sociedad como una simple dinámica de vigilar y castigar, por el contrario, más allá de esto, el fin de la sociedad, es viabilizar caminos de crecimiento que aporten al desarrollo del ser humano, por lo cual, la razón de ser del ejercicio profesional debe encaminarse hacia la consolidación del ideal utópico en aras de garantizar el sano devenir del ser humano.

¿Es posible entonces, desde la psicología jurídica aportar a los procesos de resignificación de la mujer, considerando el concepto utópico planteado por Fajardo y García (2011), como punto de partida para la realización de cambios sociales? ¿Está preparada la academia para favorecer la formación de psicólogos jurídicos a la luz de estos nuevos retos? ¿Pueden las disciplinas converger y trabajar mancomunadamente por el respeto de los derechos y la realización de políticas y programas a la luz de aplicaciones diferentes del derecho?

Estos son los nuevos retos que como disciplina se deben responder, para favorecer el adecuado desarrollo e implementación de la norma, siempre en busca del mejoramiento continuo de la vida del ser humano, garantizando su libertad y autonomía del ser. La intención, es ir más allá de protocolos jurídicos, que en ocasiones debilitan el buen ejercicio del quehacer profesional y encaminar la consecución de formas más plausibles, amenas y humanas de referir la imbricación del derecho sobre el sentido de lo humano y su relación con el ámbito jurídico y social.

A la luz de lo anterior, queda entonces abierta la posibilidad a nuevas discusiones que alimenten el sentir utópico sobre la razón y el sentido de la psicología jurídica, que permitan alcanzar su consolidación en aras de un mejor vivir para la sociedad. 


\section{REFERENCIAS}

Arboleda, M. (2011). Código penal y de procedimiento penal. Bogotá: Leyer Editores

Corte Constitucional de Colombia. (1996). Sentencia C -430/96. Magistrado Ponente Carlos Gaviria. Régimen Penal Colombiano 2006

Echeburúa, E.; Corral, P.; Amor, P. (2002) Evaluación del daño psicológico en las víctimas de delitos violentos. Psicothema Vol. 14 (Sup) 139-146 recuperado el [15-03-2012] en http://www.psicothema.com/pdf/3484.pdf

El tiempo.com Mujeres quemadas con ácido muestran sus rostros para protestar. Consultado el [08-03-2012] en http://www.eltiempo.com/politica/ARTICULO-WEBNEW NOTA INTERIOR-11295521.html

El tiempo.com (2012). Presidente Santos y gobernadores firmaron un acuerdo por la mujer. Consultado el [08-03-2012] en http://www.eltiempo.com/politica/presidente-santos-ygobernadores-firmaron-un-acuerdo-por-la-mujer- 11294342-4

El tiempo.com (2011). Abren cuenta para ayudar en tratamiento de joven quemada con ácido. El ataque contra Natalia Valencia será evaluado este lunes en un consejo de seguridad.

Consultado

el

[08-03-2012]

en http://www.eltiempo.com/archivo/documento/CMS-10156072

Fajardo, L. y García, L. (2011). Utopía y jurisprudencia Constitucional. Bogotá: Universidad Santo Tomás

Neira, A. (2011). Relatos de mujeres atacadas con ácido por ex compañeros sentimentales. Conozca casos de ataques de este tipo que han sucedido en Colombia. Consultado el [1003-2012] en http://www.eltiempo.com/archivo/documento/CMS-10834444

Régimen penal colombiano (2006). Legis editores S.A

Santos, J. M. (2012). 8 de marzo: día de la mujer. Mensaje Presidente Juan Manuel Santos. Consultado el [09-03-2012] en http://201.234.245.148/otros/men/

Soria, Miguel (2007). Manual de psicología jurídica e investigación criminal. Madrid: Ediciones Pirámide

Valbuena, J. (2012). Mujeres quemadas con ácido aplauden condenas altas por este crimen. Consultado el [18-03-2012] en http://www.eltiempo.com/politica/ARTICULO-WEBNEW NOTA INTERIOR-11376753.html 